\title{
泰山4种优势造林树种细根分解对细菌群落结构的 影响
}

路 颖 李坤倪瑞强梁强李传荣 张彩虹

国家林业局泰山森林生态系统定位研究站，山东泰安 271018; 黄河下游森林培育国家林业局重点实验室，山东泰安 271018

摘 要 为了理解细菌群落结构和多样性对森林生态系统细根调落物分解的影响, 该研究以泰山4种主要优势造林树种刺槐 (Robinia pseudoacacia)、麻栋(Quercus acutissima)、油松(Pinus tabulaeformis)和赤松(Pinus densiflora)为研究对象, 采用调落物 分解袋法及Illumina Miseq测序平台对细菌16S rDNA V4-V5区扩增产物进行双端测序, 分析了4种树种细根分解对细菌群落 结构及多样性的影响。结果表明: (1) 4 种植物细根分解速率差异显著, 阔叶树种分解速率显著高于针叶树种, 表现为刺槐 $>$ 麻 栋>油松>赤松。(2) 4 个树种细菌序列操作分类单元(OTU)、观测到的物种数、Ace指数和系统发育多样性之间差异显著, 且 阔叶树种刺槐和麻栎显著低于针叶树种赤松和油松。4种细根分解的细菌群落结构存在极显著差异。细根初始碳(C)含量、木 质素:氮 $(\mathrm{N})$ 和 $\mathrm{C}: \mathrm{N}$ 对细菌群落结构的影响较大。(3)细菌群落相对丰度在 $5 \%$ 以上的优势类群是变形菌门、放线菌门、拟杆菌门、 酸杆菌门, 且变形菌门、酸杆菌门在 4 个树种之间差异显著, 特别是阔叶树种变形菌门显著高于针叶树种。在纲水平上, $\alpha$-变 形菌纲、 $\beta$-变形菌纲、 $\gamma$-变形菌纲、不明放线菌纲、鞘脂杆菌纲为主要的优势纲, 其中 $\alpha$-变形菌纲、不明放线菌纲在 4 个树种 之间差异显著。(4) Pearson相关性分析表明, 细菌优势门和纲相对丰度受到调落物初始化学性质的影响, 特别是变形菌门和 $\alpha$ 变形菌纲; 变形菌门和 $\alpha$-变形菌纲相对丰度与细根分解速率显著正相关。穴余分析结果也显示, 细根初始 $\mathrm{N}$ 、磷 $(\mathrm{P})$ 含量和木 质素含量对细菌群落结构的影响较大。研究结果有助于理解细菌群落结构和多样性对森林生态系统细根调落物分解的影响。 关键词 分解; 细根; 细菌群落; 多样性

路颖, 李坤, 倪瑞强, 梁强, 李传荣, 张彩虹 (2018). 泰山4种优势造林树种细根分解对细菌群落结构的影响. 植物生态学报, 42, 1200-1210. DOI: $10.17521 /$ cjpe. 2018.0120

\section{Effects of fine root decomposition on bacterial community structure of four dominated tree species in Mount Taishan, China}

LU Ying, LI Kun, NI Rui-Qiang, LIANG Qiang, LI Chuan-Rong, and ZHANG Cai-Hong*

Taishan Forest Ecosystem Research Station of the State Forestry Administration, Tai'an, Shandong 271018, China; and Key Laboratory of State Forestry Administration for Silviculture of the Lower Yellow River, Tai'an, Shandong 271018, China

\begin{abstract}
Aims Microorganisms play a crucial role in the litter decomposition process in terrestrial ecosystems. Understanding the independent and interactive relationship between fine root decomposition and bacteria community related to substrate characteristics can help to predict the consequences of changes on ecosystem function. Therefore, the aim of this study was to identify fine roots' influences on rhizosphere microbial structure and diversity.

Methods The decomposition of root litters of four dominant tree species of Mount Taishan (Robinia pseudoacacia (RP), Quercus acutissima (QA), Pinus tabulaeformis (PT) and Pinus densiflora (PD)) was tested in a Yaoxiang Forest Farm. Using Illumina high-throughput sequencing of 16S rRNA genes, bacterial community composition was determined. Composition, diversity and relative abundance of bacteria were calculated for per fine root litter.

Important findings (1) Fine root litter decomposition differed significantly among different root types. There was no difference in decomposition rate between broad-leaved species and conifer species. In all species, fine roots of RP and QA were more strongly decomposed than that of PT and PD, and these differences were significant (RP > QA > PT > PD). (2) The number of observed species, operational taxonomic units, Ace index and phylogenetic diversity in broad-leaved species were significantly lower than that in coniferous species. Bacterial

收稿日期Received: 2018-05-21 接受日期Accepted: 2018-10-31

基金项目：国家自然科学基金(31500362和31570705)、山东省联合专项(ZR2014CL005)和山东省“双一流”奖补资金(SYL2017XTTD03)。Supported by the National Natural Science Foundation of China (31500362 and 31570705), the Joint Special Project of Shandong Province (ZR2014CL005), and the Funds of Shandong "Double Tops" Program (SYL2017XTTD03).

* 通信作者Corresponding author (zhangcaihong78@163.com)
\end{abstract}


logenetic diversity in broad-leaved species were significantly lower than that in coniferous species. Bacterial community structure differed significantly among four species for root decomposition. Initial carbon (C), lignin:nitrogen $(\mathrm{N})$ and $\mathrm{C}: \mathrm{N}$ in fine root had a great influence on the bacterial community structure. (3) At the phylum level, a total of 4 phyla were dominant ( $>5 \%$ across all species). Based on the average relative abundance, the most abundant phyla were Proteobacteria, Actinomyces, Bacteroidetes and Acidobacteria. Proteobacteria's and Acidbacteria's abundance were significantly different among the four species. Particularly, the Proteobacteria of broad-leaved species was significantly higher than that of coniferous species. At the class level, a wide range of classes dominated. Based on the average relative abundance, the most abundance classes were Alphaproteobacteria, Betaproteobacteria, Gammaproteobacteria, unidentified-Actinobacteria and Sphingobacteriia. Alphaproteobacteria and unidentified-Actinobacteria had significant differences among the four species. (4) Pearson correlation analysis showed that the relative abundance of dominant phylum and class was affected by the initial properties of root litter, especially the Proteobacteria and Alphaproteobacteria. In addition, there was a significant positive correlation between fine root decomposition rate and relative abundance of Proteobacteria and Alphaproteobacteria. Redundancy analysis (RDA) also demonstrated that the initial properties of fine root litter (initial N, P, $\mathrm{C}: \mathrm{N}$ ) had significant effects on the structures of bacterial community. These results can improve understanding the links between fine root litter decomposition and functional microbial communities.

Key words decomposition; fine root; bacterial community; diversity

Lu Y, Li K, Ni RQ, Liang Q, Li CR, Zhang CH (2018). Effects of fine root decomposition on bacterial community structure of four dominated tree species in Mount Taishan, China. Chinese Journal of Plant Ecology, 42, 1200-1210. DOI: 10.17521/cjpe.2018.0120

森林调落物的累积和分解是森林生态系统养分 循环的重要环节, 是光合作用固定碳(C)返回到大 气的主要途径(Coûteaux et al., 1995), 并且维持生态 系统中养分循环过程, 为土壤动物、微生物提供食 物来源, 为植物生长提供必要的养分 (张彩虹等, 2011), 长期以来受到研究者的广泛关注(张彩虹等, 2011; Gui et al., 2017; 罗永清等, 2017)。近10年, 对 森林叶片调落物分解的研究大量涌现(Chapman \& Koch, 2007; Wymore et al., 2018), 但是, 根系分解 往往被忽略。相比于对地上组织分解的研究, 特殊 的位置导致对根系调落物的研究相对滞后, 但是植 物根系周转迅速, 特别是细根, 其周转速度更快, 约占总净初级生产量的33\% (罗永清等, 2017; Shen et al., 2017), 且根系调落物数量庞大, 其更新过程 可产生 5 倍于地上调落物的调落量(Grier et al., 1981)。可见, 对根系调落物分解的研究对整个森林 生态系统土壤有机质的形成和养分循环至关重要。

调落物形成后, 通过物理过程、非生物化学过 程、生物过程进行分解, 前人的研究发现, 在大的空 间尺度上, 气候条件在控制调落物分解中起更加显 著的作用(Meentemeyer, 1978; Tuomi et al., 2009); 在小尺度上, 调落物质量 $($ 如氮 $(\mathrm{N})$ 含量、 $\mathrm{C}: \mathrm{N}$ 、木质 素含量等)和微生物群落组成是主要的影响因素 (Taylor et al., 1989; Wymore et al., 2018)。近年来, 研 究表明微生物能代谢和转化叶片C形成微生物生物
量(Gessner et al., 1999), 在调落物分解过程中发挥 着不可替代的作用(Sun et al., 2017)。关于调落物分 解过程中微生物的研究主要集中在土壤微生物群落 结构(Sun et al., 2017), 而对分解过程中调落物中微 生物群落结构的研究涉及较少(张明锦等, 2015)。在 土壤环境中细菌是数量最大、种类最多的微生物, 其生物学特性各异, 功能多样, 繁殖迅速, 对土壤 肥力的形成、植物营养的转化有极其重要的作用 (Kennedy, 1999; 丁新景等, 2017)。早期的研究结果 显示, 细菌对调落物分解的作用方式与真菌有明显 差别, 在分解的初始阶段主要是真菌起作用, 而分 解后期主要是耐受能力更强的细菌起作用(Wardle et al., 2004; Chapman \& Koch, 2007)。随后基于苂光 定量PCR的研究表明, 细菌在调落物分解早期同样 具有重要作用, 前期的研究低估了细菌在调落物分 解中的作用(Adam et al., 2013; 张明锦等, 2015)。且 前人的结论主要是基于叶片调落物基质, 而对于根 系分解过程中微生物群落结构的变化尚未见报道。

长期以来, 由于受技术条件的限制, 对微生物 的研究结果不能真实、全面地反映各生态系统中微 生物群落多样性和结构及微生物不同类型所起的作 用, 特别是在调落物分解过程中(荣丽等, 2009)。高 通量测序技术打破了原有技术的局限, 无需分离单 一菌株, 直接在基因水平上挖掘环境中的微生物信 息，具有成本低、通量高、信息丰富等优点。近年 
来, 已经广泛用于不同生态系统微生物群落结构的 测定, 如空气(孙翠丽等, 2017)、土壤(丁新景等, 2017; Sun et al., 2017)、水域(Zhao et al., 2017)等。 但是高通量测序技术在调落物分解的研究中应用相 对较少, 特别是细根分解中的应用更少。因此, 本研 究采用高通量测序技术, 研究了泰山4种优势造林 树种细根分解过程中细菌群落组成, 对比分析了 4 个树种细菌优势种群、细菌多样性的差异, 同时揭 示了细根分解速率与初始化学性质和细菌群落结构 之间的相关关系, 为研究细根调落物分解的微生物 控制机制提供理论依据。

\section{1 材料和方法}

\section{1 研究区概况}

研究地点位于泰山药乡林场的森林生态系统观 测研究站 $\left(117.08-117.15^{\circ} \mathrm{E}, 36.28^{\circ}-36.33^{\circ} \mathrm{N}\right)$ 。该地 属于暖温带大陆性季风气候, 年平均气温 $18.5^{\circ} \mathrm{C}$, 年降水量758 mm, 主要集中在6-9月。中低山丘陵 地貌, 主要土壤类型为中性至酸性棕壤, 土层较薄, 厚度为 $20-30 \mathrm{~cm}$ 。地带性植被类型为暖温带落叶阔 叶林, 目前森林覆盖率达 $81.57 \%$, 植被覆盖率达 $90 \%$ 以上。主要森林类型为油松(Pinus tabulaeformis) 林、侧柏 (Platycladus orientalis) 林、赤松 (Pinus densiflora)林、刺槐(Robinia pseudoacacia) 林、麻栋 (Quercus acutissima) 林。

\section{2 研究方法}

\subsection{1 试验设计及样品分析}

样品收集: 本项目采用泰山站附近4种主要树 种的细根作为分解的材料。为了保证后期分解试验 的顺利开展, 在试验开始之前收集刺槐 $(\mathrm{RP})$ 、麻栎 $(\mathrm{QA}) 、$ 赤松 $(\mathrm{PD})$ 和油松 $(\mathrm{PT})$ 的细根。对于根分解, 采 用直径小于 $2 \mathrm{~mm}$ 的细根, 因为刚调落的根很难从 已经分解一段时间的根中分离, 所以采用活根进行 试验。目前, 国际上大量根分解研究已经采用活根 进行试验(McLaren \& Turkington, 2010)。细根的采 样于 2015 年 8 月植物生长旺盛的季节进行, 4 种树种 选择代表性的植株, 采用挖根法收集直径小于 $2 \mathrm{~mm}$ 的细根, 采样后去除表层的土壤。将收集到的 细根置于室内风干备用。取小部分样品在 $65{ }^{\circ} \mathrm{C}$ 烘箱 内烘干至恒质量, 分解底物风干质量: 烘干质量得 到换算系数(计算含水量)。并测定初始样品的 C、N、 $\mathrm{P}$ 和木质素含量。
试验布设及取样：采用通用的调落物袋的方 法。调落物袋的大小为 $15 \mathrm{~cm} \times 15 \mathrm{~cm}$ (网孔大小为 $1 \mathrm{~mm} \times 1 \mathrm{~mm})$, 每个调落物袋中装入风干的样品 $6 \mathrm{~g} 。 2016$ 年7月, 采用随机区组设计将分解袋布设于 6 个重复的试验区内, 小区大小为 $10 \mathrm{~m} \times 10 \mathrm{~m}$, 相 邻小区设置 $5 \mathrm{~m} \times 5 \mathrm{~m}$ 的隔离带, 每个小区每个树种 各放1袋。将样品置于地下 $15 \mathrm{~cm}$ 深处, 方法是将铁 锹以 $45^{\circ}$ 倾角插入土壤中, 将土壤㧼开(尽量不破坏 土壤结构), 然后将调落物分解袋沿裂缝滑入土壤 中。试验持续时间为一年, 2017年7月取样。取样时, 每个小区中每种树种取 1 袋, 清除调落物表面黏附 的土壤和长入的杂草。其中3袋重复样品标记后立即 存于液氮中, 用于测定微生物细菌群落。另外的3袋 重复样品在实验室内去除其中的杂质, $65{ }^{\circ} \mathrm{C}$ 烘干至 恒质量, 然后称质量, 并测定其灰分含量, 用于矫 正干质量。

\subsection{2 样品DNA提取和测序}

采用 CTAB方法对样本基因组DNA进行提取 (Hultman et al., 2015), 具体操作为: 吸取 $1000 \mu \mathrm{L}$ CTAB裂解液至 $2.0 \mathrm{~mL}$ EP管里, 加入 $20 \mu \mathrm{L}$ 溶菌酶, 将适量的样品加入裂解液中, $65{ }^{\circ} \mathrm{C}$ 水浴, 期间颠倒 混匀数次, 以使样品充分裂解。离心取 $950 \mu \mathrm{L}$ 上清 液, 加入与上清液等体积的酚 $(\mathrm{pH}$ 值 8.0): 氯仿: 异戊 醇(体积比 25:24:1), 颠倒混匀, $12000 \mathrm{r} \cdot \mathrm{min}^{-1}$ 离心 $10 \mathrm{~min}$ 。取上清液, 加入等体积的氯仿:异戊醇(体积 比24:1), 颠倒混匀, $12000 \mathrm{r} \cdot \mathrm{min}^{-1}$ 离心 $10 \mathrm{~min}$ 。吸取 上清液至 $1.5 \mathrm{~mL}$ 离心管里, 加入上清液 $3 / 4$ 体积的异 丙醇, 上下摇晃, $-20{ }^{\circ} \mathrm{C}$ 沉淀 $60 \mathrm{~min}$, 然后 12000 $\mathrm{r} \cdot \mathrm{min}^{-1}$ 离心 $10 \mathrm{~min}$, 倒出液体。用 $1 \mathrm{~mL} 75 \%$ 乙醇洗 涤2次, 剩余的少量液体再次离心收集, 然后用枪头

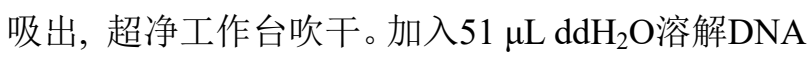
样品。加 $1 \mu \mathrm{L}$ RNase A消化RNA, $37^{\circ} \mathrm{C}$ 放置 15 min。 之后用琼脂糖凝胶电泳检测DNA纯度和浓度, 取适 量样品于离心管中, 用无菌水稀释样品至 $1 \mathrm{ng} \cdot \mu \mathrm{L}^{-1}$ 。以稀释后的基因组DNA为模板, 利用带 条 码 (Barcode) 的 特异 引物 $515 \mathrm{~F}\left(5^{\prime}\right.$ GTGCCAGCMGCCGCGGTAA-3') 与 907R(5'-CCGT CAATTCCTTTGAGTTT-3')扩增其V4-V5 区基因片 段。反应体系为 $30 \mu \mathrm{L}$, 其中含 $15 \mu \mathrm{L}$ Phusion Master Mix (2×), $3 \mu \mathrm{L}$ Primer $\left(2 \mu \mathrm{mol} \cdot \mathrm{L}^{-1}\right), 10 \mu \mathrm{L}$ 基因组 DNA $\left(1 \mathrm{ng} \cdot \mu \mathrm{L}^{-1}\right), 2 \mu \mathrm{L} \mathrm{H}_{2} \mathrm{O}$ 。PCR反应程序为: $98{ }^{\circ} \mathrm{C}$ 预变性 $1 \mathrm{~min} ; 30$ 个循环包括 $\left(98{ }^{\circ} \mathrm{C}, 10 \mathrm{~s} ; 50{ }^{\circ} \mathrm{C}, 30 \mathrm{~s}\right.$; 
$\left.72{ }^{\circ} \mathrm{C}, 30 \mathrm{~s}\right) ; 72{ }^{\circ} \mathrm{C}$ 延伸 5 min。扩增产物用 $1.5 \%$ 的琼 脂糖凝胶电泳验证大小并回收纯化, 凝胶回收采用 试剂盒GeneJET (Thermo Scientific), 按照说明书操 作。纯化结束后的目的片段用Biodrop核酸检测仪 (Biochrom, Cambridge, UK)测定浓度和质量。相同 处理样品的纯化产物进行等质量混合, 均匀混合后 送至北京诺禾致源测序公司, 利用Illumina Miseq平 台进行测序。

\subsection{3 养分测定}

调落物中C、N含量采用元素分析仪(ECS4010, Costech, Firenze, Italy), P含量采用酸溶-钼锑抗比色 法测定, 木质素含量采用逐步提取和质量分析法 (GB/T 2677.8-1994, GB/T 10337-2008)。

\section{3 数据处理}

根据Barcode序列和PCR 扩增引物序列从下机 数据中拆分出各样品数据, 截去Barcode和引物序 列后使用 FLASH (V1.2.7, http://ccb.jhu.edu/ software/FLASH/)对每个样品的reads进行拼接, 得 到的拼接序列为原始Tags数据(Raw Tags); 拼接得 到的Raw Tags, 需要经过严格的过滤处理得到高质 量的Tags数据(Clean Tags)。利用Uparse软件(Uparse v7.0.1001)对所有样品的全部有效数据进行聚类, 默认以 $97 \%$ 的一致性将序列聚类成为操作分类单元 (OTU), 同时依据其算法原则, 篮选OTU中出现频 数最高的序列作为OTU的代表序列。各样品的有效 序列数量分别为: 刺槐73 723、61362、36 056, 麻 栎: 58 700、54 741、35 181, 赤松: $57842 、 70613$ 、 51 230, 油松: 58 831、50 694、47 499。计算 $\alpha$ 多样 性指数之前进行抽平处理, 即每个样品随机抽取相 同的序列数(本文为最小有效序列数)进行后续计 算。利用Mothur软件(Version 1.35.1)计算样品的 $\alpha$ 多 样性指数, 反映不同树种根系调落物分解过程中细 菌群落的丰度和多样性, 包括Chao1指数、Ace指数、 Coverage指数、系统发育多样性值和Shannon指数。利
用 $\mathrm{R}$ 软件(Version3.5.1)完成群落结构分析，其中采用 非度量多维尺度(Nonmetric Multidimensional Scaling, NMDS) 分析细根分解时细菌群落结构的差异, 用 ANOSIM 非参数检验分析各处理间的差异显著性, 并采用冗余分析(RDA)探讨细菌群落结构与细根初 始化学性质之间的关系。运用SPSS 17.0软件进行统 计分析, 采用单因素方差分析比较4种细根调落物 各初始化学元素含量、分解速率 $(k)$ 、细根分解一年 后各树种细菌多样性之间的差异显著性以及主要细 菌优势类群相对丰度在 4 种树种之间的差异显著性; 采用Pearson相关分析确定细菌群落优势门和纲相 对丰度、细根初始化学性质和细根分解速率之间的 相关性。

\section{2 结果和分析}

\section{1 不同物种细根分解过程的差异}

从表 1 可以看出, 选择的 4 种细根调落物初始化 学性质之间存在显著差异, 特别是针叶树种和阔叶 树种之间差别较大。C 含量、C:N、木质素含量表现 出针叶树种(赤松、油松)显著高于阔叶树种(刺槐、 麻栎) $(p<0.05)$; $\mathrm{N}$ 含量、 $\mathrm{P}$ 含量、 $\mathrm{N}: \mathrm{P}$ 针叶树种显著 低于阔叶树种 $(p<0.05)$, 表现为赤松 $<$ 油松 $<$ 麻栋 $<$ 刺槐。

泰山4种主要优势造林树种细根分解速率之间 差异极显著 $(p=0.001)$ 。图1可见，阔叶树种分解速 率显著高于针叶树种 $(p<0.05)$, 分解快慢表现为刺 槐>麻栋>油松>赤松。两种针叶树种的细根分解速 率之间差异不显著 $(p>0.05)$, 两种阔叶树种的细根 分解速率之间差异也不显著 $(p>0.05)$ 。

\section{2 细根分解对细菌 $\alpha$ 多样性的影响}

从表 2 可以看出, 细根分解一年后微生物基因 序列的覆盖率(指文库检测到的微生物种群在环境 样品所有微生物中所占的比例)均达到 $97 \%$ 以上，说 明所测定序列可以充分反映样本细菌群落的种类和

表1 泰山4个树种细根调落物初始化学元素含量的差异(平均值土标准误差, $n=3$ )

Table 1 Differences in initial element contents of fine root litter (mean $\pm S E, n=3$ )

\begin{tabular}{|c|c|c|c|c|c|c|}
\hline 树种 Species & $\mathrm{C}(\%)$ & $\mathrm{N}(\%)$ & $\mathrm{P}(\%)$ & $\mathrm{C}: \mathrm{N}$ & $\mathrm{N}: \mathrm{P}$ & 木质素 Lignin (\%) \\
\hline $\mathrm{RP}$ & $48.77 \pm 0.33^{c}$ & $3.36 \pm 0.002^{\mathrm{a}}$ & $0.53 \pm 0.05^{\mathrm{a}}$ & $14.51 \pm 0.09^{d}$ & $6.36 \pm 0.34^{\mathrm{a}}$ & $29.59 \pm 0.47^{\mathrm{c}}$ \\
\hline QA & $46.39 \pm 0.17^{\mathrm{d}}$ & $1.08 \pm 0.008^{\mathrm{b}}$ & $0.46 \pm 0.01^{\mathrm{a}}$ & $43.02 \pm 0.17^{\mathrm{c}}$ & $2.34 \pm 0.05^{\mathrm{b}}$ & $33.78 \pm 0.60^{b}$ \\
\hline PD & $54.65 \pm 0.17^{\mathrm{a}}$ & $0.38 \pm 0.009^{\mathrm{d}}$ & $0.39 \pm 0.03^{\mathrm{b}}$ & $142.48 \pm 3.72^{\mathrm{a}}$ & $1.00 \pm 0.07^{\mathrm{c}}$ & $38.34 \pm 0.30^{\mathrm{a}}$ \\
\hline PT & $49.96 \pm 0.13^{\mathrm{b}}$ & $0.85 \pm 0.004^{\mathrm{c}}$ & $0.41 \pm 0.03^{\mathrm{b}}$ & $59.04 \pm 0.19^{b}$ & $2.10 \pm 0.14^{\mathrm{b}}$ & $37.78 \pm 0.15^{\mathrm{a}}$ \\
\hline
\end{tabular}

PD, 赤松; PT, 油松; QA, 麻栎; RP, 刺槐。不同小写字母代表不同树种之间差异显著 $(p<0.05)$ 。

PD, Pinus densiflora; PT, Pinus tabulaeformis; QA, Quercus acutissima; RP, Robinia pseudoacacia. Different lowercase letters represent significant differences among different species $(p<0.05)$. 


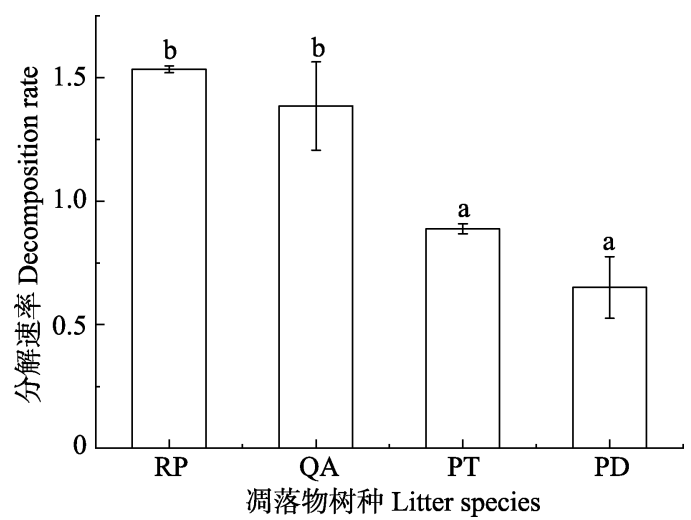

图 1 泰山 4 种植物分解速率之间的差异 (平均值土标准误 差)。PD, 赤松; PT, 油松; QA, 麻栎; RP, 刺槐。不同小写字 母代表不同树种之间差异显著 $(p<0.05)$ 。

Fig. 1 Difference in decomposition rate among four litter species (mean $\pm S E$ ) in Mount Taishan. PD, Pinus densiflora; PT, Pinus tabulaeformis; QA, Quercus acutissima; RP, Robinia pseudoacacia. Different lowercase letters represent significant differences among different species $(p<0.05)$.

结构。 4 个树种细根分解一年后细菌丰富度(OTU、 观测到的物种数(指由OTU比对数据库得出的物种 的数量)和Ace)和系统发育多样性之间有显著差异 $(p<0.05)$, 且阔叶树种刺槐和麻栎显著低于针叶树 种赤松和油松。

从表 3 可见, 初始调落物 $\mathrm{C}$ 含量与细菌群落 $\alpha$ 多 样性指数的相关性最大, 能解释物种数 $78.1 \%(p=$ 0.004), Chao1 73.7\% ( $p=0.006)$, Ace 76.4\% ( $p=$ $0.005)$, 系统发育多样性 $68.7 \%(p=0.011)$ 的变异。

\section{3 细根分解对细菌 $\beta$ 多样性的影响}

细菌群落的NMDS分析结果(图2)显示, 4 个树 种明显分布在不同的象限, 表明细菌群落结构有明 显差异。ANOSIM非参数检验分析结果也显示, 4 个 树种细根分解的细菌群落结构存在极显著差异 $(r=$ $0.7006 ; p=0.001)$ 。细菌群落结构与细根初始化学 性质之间的 RDA 结果显示, 细根初始 $\mathrm{C}$ 含量、木质 素:N和C:N对细菌群落结构的影响较大。麻栎调落 物内细菌群落结构与初始P含量相关性最大, 刺槐 和赤松细菌群落结构与初始木质素: $\mathrm{N}$ 和 $\mathrm{C}: \mathrm{N}$ 相关性 最大(图3)。

\section{4 细菌优势类群丰度}

高通量测序的结果显示所有样品一共获得 656472 条有效序列，其中最少的样品序列为 35181 条, 最多的样品序列为 73723 条(平均序列条数为 54 706条)。这些序列的 $97.2 \%$ 可以分类到不同的细 菌门类, $2.8 \%$ 分类到古菌门类，隶属于 34 门 87 纲, 121 目, 242科, 403属, 216种。本研究将着重从门水平 和纲水平对不同树种样品的细菌群落进行统计分 析。在门水平上, 细根调落物分解中细菌类群多集 中于变形菌门(Proteobacteria, 63.3\%)、放线菌门 (Actinobacteria, 14.1\%)、拟杆菌门(Bacteroidetes, $7.0 \%$ )、酸杆菌门(Acidobacteria, $6.9 \%$ ), 它们的平均 相对丰度大于 $5 \%$, 其中变形菌门占绝对优势。此外

表2 细根分解一年后泰山细菌多样性统计分析(平均值士标准误差, $n=3$ )

Table 2 Statistical analysis of bacterial diversity in Mount Taishan after one year of fine root decomposition (mean $\pm S E, n=3)$

\begin{tabular}{|c|c|c|c|c|c|c|}
\hline $\begin{array}{l}\text { 树种 } \\
\text { Species }\end{array}$ & $\begin{array}{l}\text { 物种数 NO. of } \\
\text { observed species }\end{array}$ & 覆盖率Coverage (\%) & $\begin{array}{l}\text { Chaol指数 } \\
\text { Chao1 index }\end{array}$ & $\begin{array}{l}\text { Ace指数 } \\
\text { Ace index }\end{array}$ & $\begin{array}{c}\text { 系统发育多样性 } \\
\text { Phylogenetic diversity }\end{array}$ & $\begin{array}{l}\text { Shannon-Wiener指数 } \\
\text { Shannon-Wiener index }\end{array}$ \\
\hline $\mathrm{RP}$ & $2149 \pm 71^{\mathrm{a}}$ & $98.6 \pm 0.1^{\mathrm{b}}$ & $3088.0 \pm 140.4^{\mathrm{ab}}$ & $3062.2 \pm 143.5^{\mathrm{ab}}$ & $159.2 \pm 4.2^{\mathrm{a}}$ & $8.38 \pm 0.59^{\mathrm{a}}$ \\
\hline QA & $1970 \pm 120^{\mathrm{a}}$ & $97.7 \pm 0.2^{\mathrm{a}}$ & $2824.2 \pm 88.5^{\mathrm{a}}$ & $2843.8 \pm 62.0^{\mathrm{a}}$ & $147.8 \pm 7.6^{\mathrm{a}}$ & $8.14 \pm 0.16^{\mathrm{a}}$ \\
\hline PD & $2759 \pm 25^{\mathrm{b}}$ & $98.3 \pm 0.2^{\mathrm{ab}}$ & $3544.7 \pm 50.3^{c}$ & $3530.6 \pm 34.3^{c}$ & $198.6 \pm 5.1^{\mathrm{b}}$ & $8.81 \pm 0.35^{\mathrm{b}}$ \\
\hline PT & $2568 \pm 39^{b}$ & $97.6 \pm 0.2^{\mathrm{a}}$ & $3395.0 \pm 2.2^{\mathrm{bc}}$ & $3341.9 \pm 68.4^{\mathrm{bc}}$ & $193.1 \pm 3.2^{\mathrm{b}}$ & $8.88 \pm 0.18^{b}$ \\
\hline
\end{tabular}

PD，赤松; PT，油松; QA，麻栎; RP，刺槐。不同小写字母代表不同树种之间差异显著 $(p<0.05)$ 。

PD, Pinus densiflora; PT, Pinus tabulaeformis; QA, Quercus acutissima; RP, Robinia pseudoacacia. Different lowercase letters represent significant differences among different species $(p<0.05)$.

表3 分解一年后细菌 $\alpha$ 多样性与调落物初始化学性质之间的相关分析

Table 3 Correlation analysis between bacterial $\alpha$ diversity and the initial properties of litter after one year of decomposition

\begin{tabular}{|c|c|c|c|c|c|c|}
\hline & $\mathrm{C}(\%)$ & $\mathrm{N}(\%)$ & $\mathrm{P}(\%)$ & $\mathrm{C}: \mathrm{N}$ & $\mathrm{N}: \mathrm{P}$ & 木质素 Lignin (\%) \\
\hline 物种数 NO. Of observed species & $0.884^{* *}$ & -0.541 & $0.679^{*}$ & $0.790^{*}$ & -0.496 & $0.726^{*}$ \\
\hline 覆盖率 Coverage $(\%)$ & 0.331 & 0.437 & -0.482 & 0.126 & 0.517 & -0.344 \\
\hline Chao1指数 Chaol index & $0.858^{* *}$ & -0.413 & 0.608 & $0.706^{*}$ & -0.377 & 0.642 \\
\hline Ace指数 Ace index & $0.874^{* *}$ & -0.446 & 0.593 & $0.748^{*}$ & -0.405 & $0.661^{*}$ \\
\hline 系统发育多样性 Phylogenetic diversity & $0.829^{*}$ & -0.547 & $0.744^{*}$ & $0.730^{*}$ & -0.515 & $0.749^{*}$ \\
\hline Shannon-Wiener指数 Shannon-Wiener index & 0.552 & -0.292 & 0.491 & 0.378 & -0.246 & 0.418 \\
\hline
\end{tabular}

表中数字代表相关系数; **, $p<0.01 ; *, p<0.05$ 。

The numbers in the table represent the correlation coefficient. ${ }^{* *}, p<0.01 ;^{*}, p<0.05$.

www.plant-ecology.com 


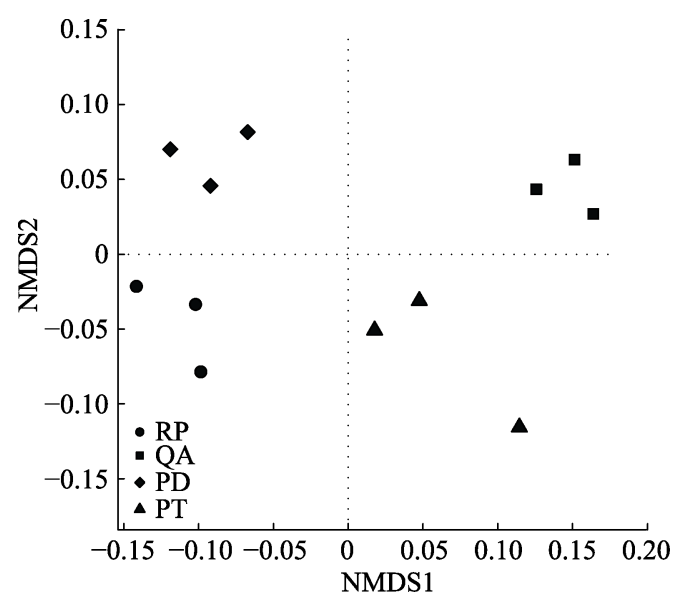

图2 细根分解一年后泰山细菌群落结构的非度量多维尺度 分析(NMDS)排序图。PD, 赤松; PT, 油松; QA, 麻栎; RP, 刺 槐。

Fig. 2 Nonmetric Multidimensional Scaling (NMDS) ordination diagram of bacterial community structure in root litter after one year of decomposition in Mount Taishan. PD, Pinus densiflora; PT, Pinus tabulaeformis; QA, Quercus acutissima; RP, Robinia pseudoacacia.

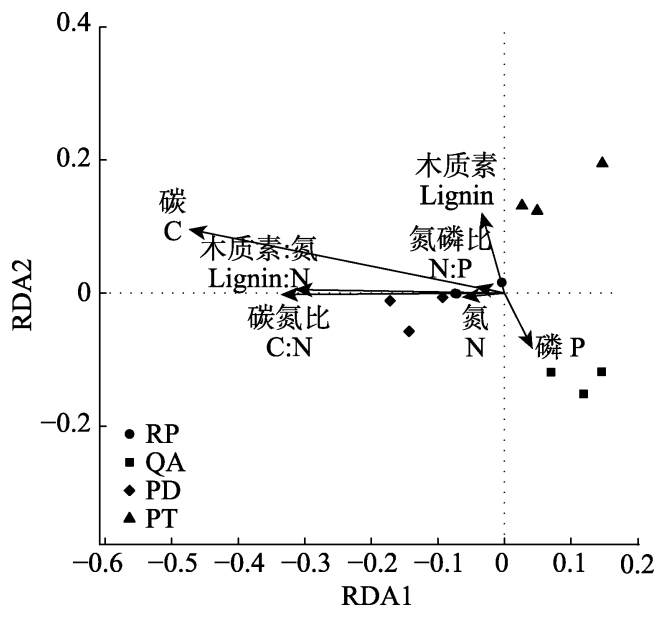

图 3 细菌群落结构与细根初始化学性质的圥余分析 (RDA)。PD，赤松; PT, 油松; QA，麻栎; RP, 刺槐。

Fig. 3 Redundancy analysis (RDA) based on bacterial community structure and the initial properties of fine root litter. PD, Pinus densiflora; PT, Pinus tabulaeformis; QA, Quercus acutissima; RP, Robinia pseudoacacia.

还发现了相对丰度小于 $5 \%$ 的其他 30 个稀有门类, 未命名的门类占 $0.4 \%$, 此外, 阔叶树种刺槐和麻栎 细根中变形菌门的相对丰度要大于针叶树种赤松和 油松。在纲水平上, 平均相对丰度大于 $5 \%$ 的类群为 $\alpha$-变形菌纲(Alphaproteobacteria, $33.1 \%$ )、 $\beta$-变形菌 纲 (Beta-proteobacteria, $14.8 \%) 、 \gamma$ - 变形菌纲 (Gammapro-teobacteria, $12.8 \%$ )、不明放线菌纲 (unidentified-Actinobacteria，9.3\%)、鞘脂杆菌纲 (Sphingobacteria, 6.1\%)。
在门的水平上, 刺槐和麻栎根分解一年后相对 丰度最大的变形菌门的丰度显著高于赤松和油松 $(p$ $<0.05)$, 麻栎和赤松的酸杆菌门的相对丰度显著高 于刺槐和油松 $(p<0.05$ )(图4B); 在纲水平上, 相对 丰度最大的是 $\alpha$-变形菌纲, 其在刺槐中最大, 显著 高于其他 3 个树种 $(p<0.05)$, 赤松的不明放线菌纲 的相对丰度显著高于其他 3 种树种 $(p<0.05$ )(图4A)。

2.5 细根分解一年后细菌优势类群相对丰度、调落 物初始化学性质和分解速率的关系

从表 4 可见, 细根分解一年后调落物内变形菌 门相对丰度与调落物初始P含量、调落物分解速率 呈显著正相关 $(p<0.05)$, 与调落物初始 $\mathrm{C}: \mathrm{N}$ 呈显著 负相关关系 $(p<0.05)$, 与其他指标没有显著的相关 性 $(p>0.05)$ 。放线菌门相对丰度仅仅与凋落物初始 $\mathrm{P}$ 含量呈显著负相关 $(p<0.05)$ 。拟杆菌门和酸杆菌 门相对丰度与调落物初始化学指标、调落物分解速 率均无显著相关性 $(p>0.05)$ 。此外, 调落物分解速 率与调落物初始各指标均存在显著相关性, 其中与 初始 $\mathrm{C}$ 含量、木质素含量和 $\mathrm{C} / \mathrm{N}$ 比呈极显著负相关关 系 $(p<0.01)$, 与初始 $\mathrm{N}$ 含量、 $\mathrm{P}$ 含量和 $\mathrm{N}: \mathrm{P}$ 呈显著正 相关关系 $(p<0.05)$ 。

从表 5 可见, 细根分解一年后调落物内 $\alpha$-变形 菌纲相对丰度与调落物初始 $\mathrm{N}$ 含量呈极显著正相关 关系 $(p<0.01)$, 与初始 $\mathrm{N}: \mathrm{P} 、$ 调落物分解速率呈显著 正相关关系 $(p<0.05)$, 与初始木质素含量、 $\mathrm{C}: \mathrm{N}$ 呈显 著负相关关系 $(p<0.05)$ 。 $\beta$-变形菌纲、 $\gamma$-变形菌纲 和鞘脂杆菌纲相对丰富与调落物初始化学指标、调 落物分解速率均无显著相关性 $(p>0.05)$ 。不明放线 菌纲相对丰度与调落物初始 $\mathrm{C}$ 含量呈极显著正相关 关系 $(p<0.01)$, 与初始 $\mathrm{C}: \mathrm{N}$ 呈显著正相关关系 $(p<$ $0.05)$ 。

对细根分解一年后细菌优势门水平上群落组成 和细根初始化学因子进行学余分析(RDA)。排序图 的前两轴解释了细根调落物内细菌群落变异程度的 93.2\%, 由此可知, 排序轴的前两轴能够真实地反 应环境因子对细菌群落的影响程度。由图5可见, 细 根初始 $\mathrm{N} 、 \mathrm{P}$ 含量和木质素含量对细菌群落结构的影 响较大。变形菌门与细根初始 $\mathrm{P}$ 含量相关性最大, 放 线菌门与细根初始木质素含量相关性最大。这也与 表4结果一致。 

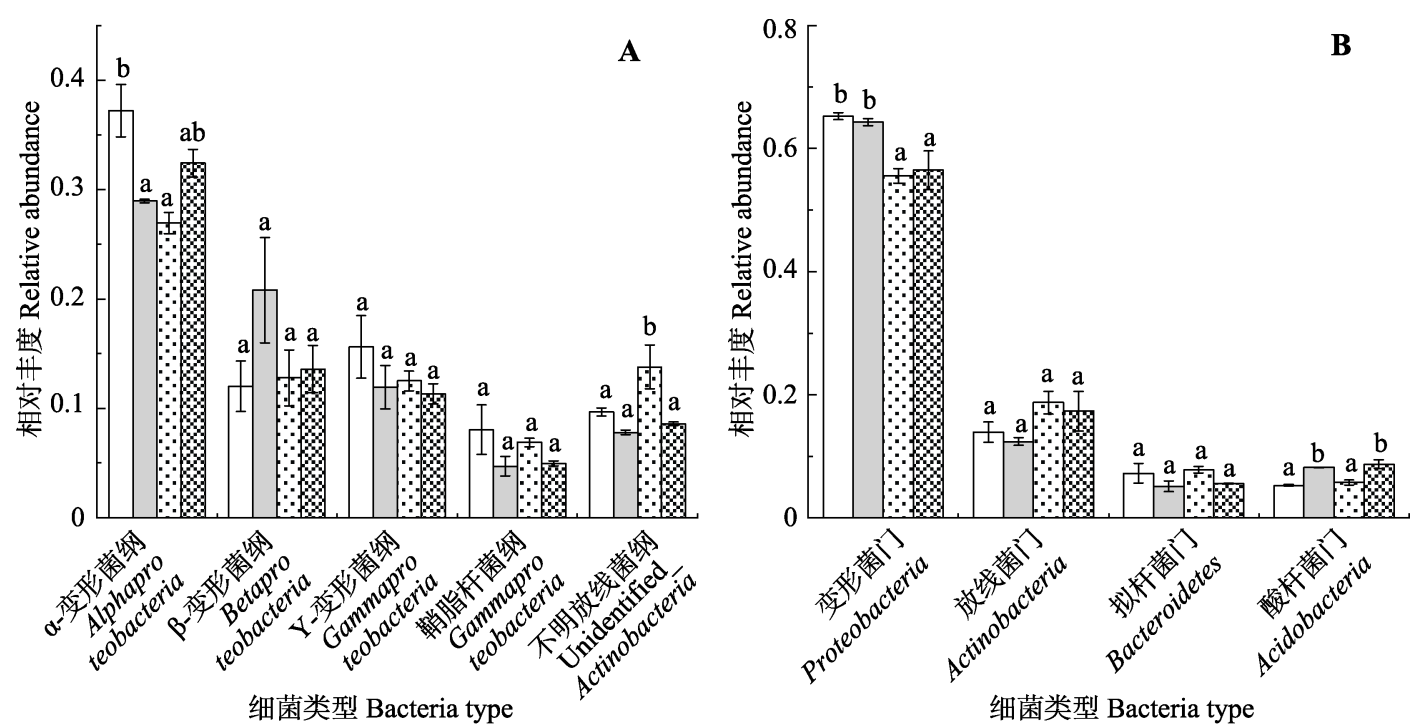

$\square \mathrm{RP} \square \mathrm{QA} \because \because \mathrm{PD}$ ॠPT

图4 泰山4个树种之间主要细菌优势类群相对丰度的差异(平均值沶准误差)。 $\mathbf{A}$, 优势纲。 $\mathbf{B}$, 优势门。 PD, 赤松; PT, 油松; QA，麻栎; RP, 刺槐。不同小写字母表示同一细菌类群不同树种的显著性差异，相同字母表示无显著性差异。

Fig. 4 Differences in relative abundances of major bacterial dominant groups among the four species in Mount Taishan $(m e a n \pm S E)$. A, Dominant classes. B, Dominant phyla. PD, Pinus densiflora; PT, Pinus tabulaeformis; QA, Quercus acutissima; RP, Robinia pseudoacacia. Different lowercase letters indicate the significant differences in different species of the same bacterial group, while the same letter indicates no significant difference.

表4 细菌优势门相对丰度与细根分解速率、调落物初始化学性质之间的相关分析

Table 4 Correlation analysis among the bacterial dominant phylum, the decomposition rate of fine roots, and the initial properties of litter

\begin{tabular}{lcccccc}
\hline 优势门 Dominant phylum & $\mathrm{C}(\%)$ & $\mathrm{N}(\%)$ & $\mathrm{P}(\%)$ & $\begin{array}{c}\text { 木质素 } \\
\text { Lignin (\%) }\end{array}$ & $\begin{array}{c}\mathrm{C}: \mathrm{N} \\
\text { 分解速率 }\end{array}$ & $\begin{array}{c}\mathrm{N}: \mathrm{P} \\
\text { Decomposition rate }\end{array}$ \\
\hline 变形菌门 Proteobacteria & -0.64 & 0.57 & $0.77^{*}$ & -0.63 & $-0.69^{*}$ & 0.52 \\
放线菌门 Actinobacteria & 0.61 & -0.32 & $-0.69^{*}$ & 0.48 & 0.50 & -0.25 \\
拟杆菌门 Bacteroidetes & 0.60 & 0.09 & 0.09 & 0.09 & 0.43 & -0.62 \\
酸杆菌门 Acidobacteria & -0.46 & -0.48 & -0.57 & 0.35 & -0.16 & -0.42 \\
分解速率 Decomposition rate & $-0.76^{* *}$ & $0.74^{* *}$ & $0.67^{*}$ & $-0.90^{* *}$ & $-0.82^{* *}$ & $0.74^{* *}$ \\
\hline
\end{tabular}

表中数字代表相关系数; **, $p<0.01 ; *, p<0.05$ 。

The numbers in the table represent the correlation coefficient. **, $p<0.01$; $^{*}, p<0.05$

表5 细菌优势纲相对丰度与细根分解速率、凋落物初始化学性质之间的相关分析

Table 5 Correlation analysis among the decomposition rate of fine roots and bacterial dominant class and the initial properties of litter

\begin{tabular}{|c|c|c|c|c|c|c|c|}
\hline 优势纲 Dominant class & $\mathrm{C}(\%)$ & $\mathrm{N}(\%)$ & $\mathrm{P}(\%)$ & $\begin{array}{c}\text { 木质素 } \\
\text { Lignin }(\%)\end{array}$ & $\mathrm{C}: \mathrm{N}$ & $\mathrm{N}: \mathrm{P}$ & $\begin{array}{c}\text { 分解速率 } \\
\text { Decomposition rate }\end{array}$ \\
\hline$\alpha$-变形菌纲 Alphaproteobacteria & -0.33 & $0.79^{* *}$ & 0.56 & $-0.71^{*}$ & $-0.73^{*}$ & $0.84^{* *}$ & $0.63^{*}$ \\
\hline$\beta$-变形菌纲 Betaproteobacteria & -0.42 & -0.18 & 0.09 & -0.00 & -0.11 & -0.21 & 0.19 \\
\hline$\gamma$-变形菌纲 Gammaproteobacteria & -0.08 & 0.49 & 0.47 & -0.37 & -0.25 & 0.43 & 0.24 \\
\hline $\begin{array}{l}\text { 不明放线菌纲 } \\
\text { unidentified-Actinobacteria }\end{array}$ & $0.84^{* *}$ & -0.25 & -0.53 & 0.37 & $0.73^{*}$ & -0.25 & -0.61 \\
\hline 鞘脂杆菌纲 Sphingobacteriia & 0.20 & 0.40 & 0.49 & -0.23 & -0.00 & 0.30 & 0.05 \\
\hline
\end{tabular}

表中数字代表相关系数; **, $p<0.01 ;{ }^{*}, p<0.05$ 。

The numbers in the table represent the correlation coefficient. ${ }^{*}, p<0.01 ;^{*}, p<0.05$.

\section{3 讨论}

研究表明细根分解后期主要是耐受能力更强 的细菌起作用(Wardle et al., 2004; Chapman \& Koch, 2007)。4种细根分解一年后的细菌群落多样性水平
较高，且存在显著差异(表2)。张明锦等(2015)对马 尾松林叶调落物分解一年时的细菌群落研究结果显 示，不同树种的Shannon-Wiener指数处于 $1-4$ 之间, 明显低于我们的结果。一方面, 可能是因为分解组 织性质差异,导致两者养分有效性存在差异，特别是 www.plant-ecology.com 


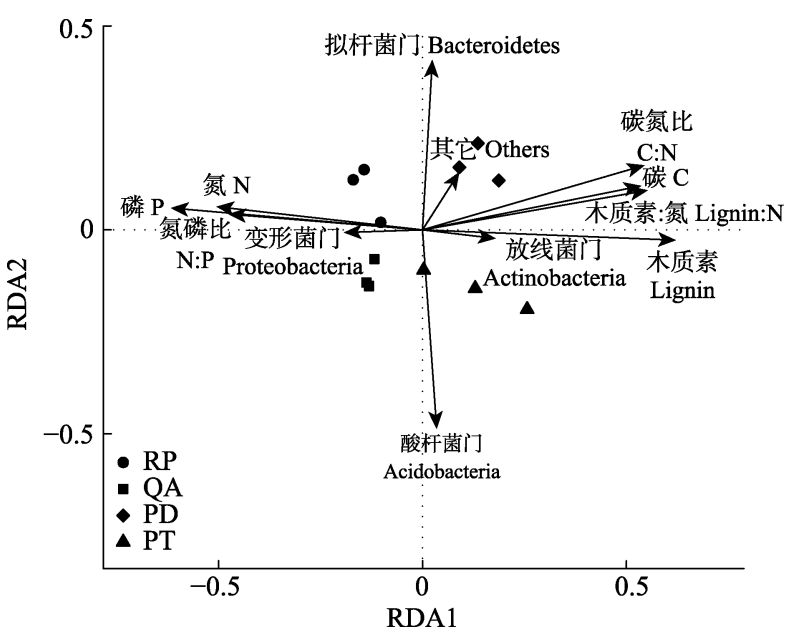

图5 细菌优势门与细根初始化学性质的圥余分析(RDA)。 PD，赤松; PT, 油松; QA, 麻栎; RP, 刺槐。

Fig. 5 Redundancy analysis (RDA) based on dominant bacterial phylum and the initial properties of fine root litter. PD, Pinus densiflora; PT, Pinus tabulaeformis; QA, Quercus acutissima; RP, Robinia pseudoacacia.

$\mathrm{P}$ 含量 (马尾松针叶为 $0.045 \%$ ), 显著低于我们的研 究结果(表1), 底物有效性较差, 所能支持的微生物 类群及数量相对较少(Taylor et al., 1989)。其次, 我 们的研究针对细根凋落物, 分解组织放置于土壤 15 $\mathrm{cm}$ 处, 而该研究针对叶调落物放置于土壤表面, 这 就造成分解环境的差异, 土壤环境变化较小, 湿度 较大，这都有利于微生物生长。叶片调落物分解的 研究结果发现针叶调落物内细菌多样性低于阔叶调 落物(张明锦等, 2015), 我们对细根调落物的分解结 果刚好与其相反, 阔叶树种(刺槐和麻栎)根系分解 中细菌群落多样性显著低于针叶树种(赤松和油 松)(表2)。细菌主要是通过分解凋落物而获取 $\mathrm{C}$ 和 $\mathrm{N}$ (张明锦等, 2015), 阔叶树种根系分解速度较快(图 $1)$, 分解一年后, 养分释放速度快, 可溶性物质含 量减少多，能支持的微生物类群及数量相对较少 (Taylor et al., 1989)。另外, 可能的原因是刺槐和麻 栎的优势菌群变形菌门的丰度显著高于油松和赤松 (图4), 其对资源的消耗增加, 细菌群落竞争加剧, 使得其他细菌丰度降低, 细菌多样性较低(丁新景 等, 2017)。ANOSIM非参数检验结果也显示阔叶树 种与针叶树种细根分解的细菌群落结构之间存在极 显著差异 $(r=0.7981 ; p=0.002)$, 我们的结果(图4) 与之一致。这也可能是导致阔叶树种根分解速率与 针叶树种根分解速率存在差异的重要原因(图1)。分 解者的活动和调落物分解速度很大程度上依赖于凋 落物质量(Wymore et al., 2018)。阔叶树种细根分解
速率显著高于针叶树种 $(p<0.05)$, 分解快慢表现为 刺槐 $>$ 麻栎 $>$ 油松 $>$ 赤松(图1)。细根分解速率与初始 $\mathrm{C}$ 含量、木质素含量和 $\mathrm{C}: \mathrm{N}$ 显著负相关，与初始 $\mathrm{N}$ 含 量、 $\mathrm{P}$ 含量和 $\mathrm{N}: \mathrm{P}$ 显著正相关(表4), 这与前人的研究 结果一致(Coûteaux et al., 1995; McLaren \& Turkington, 2010; Zhao et al., 2017)。阔叶树种初始调落 物质量显著高于针叶树种(表1), 有利于加速打开细 菌能量通道, 促进变形菌门的生长(Sauvadet et al., 2016)。这有利于加速调落物分解过程中的C、N循 环(Kersters et al., 2006)和分解速率(表4)。分解一年 后, 变形菌门、放线菌门、拟杆菌门和酸杆菌门是 主要的优势细菌门, 尤其是变形菌门平均占整个细 菌群落的 $63.3 \%$ 。前人的结果显示, 变形菌门、酸杆 菌门和放线菌门是最丰富和活跃的分解者(Gui et al., 2017), 在北方和温带森林, 这些细菌门在土壤 有机层丰富度最大(Zhang et al., 2014), 且其中大多 数细菌能降解调落物中难分解的 C (Barret et al., 2011)。变形菌门被认为是一类富营养菌, 在分解中 占优势(Sun et al., 2017), 是土壤中最常见和最丰富 的细菌(Gui et al., 2017)。阔叶树调落物产生的富营 养生境有利于其变形菌门的生长, 导致阔叶树种根 分解的变形菌门显著高于针叶树种(图4B)。 $\mathrm{P}$ 是 DNA复制和转录的重要元素, P限制将直接影响细 菌群落的生长(Elser et al., 2003)。N元素的缺乏会对 微生物的生长及活性产生负面影响(Taylor et al., 1989), 当细根分解过程中木质素含量高且土壤中 可利用 N、P含量不足时, 分解微生物的多样性将会 下降(Chigineva et al., 2009)。分解一年后, 变形菌门 相对丰度与细根初始 $\mathrm{P}$ 含量呈显著正相关, 与 $\mathrm{N}$ 含 量正相关关系(表4; 图5), 这也与变形菌门需要富 营养来满足其需求相一致。放线菌门的细菌具有细 丝状的菌丝, 这些菌丝拥有较强的次生代谢功能, 在有机质分解中起重要作用(V̌rtrovský \& Baldrian, 2015)。放线菌门相对丰度与初始P含量呈显著负相 关关系(表4), 放线菌纲相对丰度与初始 C: $\mathrm{N}$ 呈显著 正相关关系(表5), 这与Urbanová (2015)的研究一 致。放线菌门大部分属于腐生菌, 部分细菌种群具 有分解木质素和纤维素的能力(Zhao et al., 2016), 但是我们的结果并未发现放线菌门(表4)、放线菌纲 (表5)与木质素具有相关性, 可能是降解木质素的种 群相对丰度较低导致的。但是, 放线菌门相对丰度 与分解速率之间并没有明显的相关性(表4), 可能是 
由于其相对丰度远低于变形菌门(图4)。拟杆菌门的 细菌能破坏复杂的生物大分子, 因此其与木质纤维 素凋落物的分解相关(Lydell et al., 2004)。前人的研 究表明, 拟杆菌门的相对丰度在阔叶树种调落物中 比在针叶树种调落物中高(Sun et al., 2017), 我们的 结果(图4B)与之不一致。可能的原因是, 该研究通 过模拟实验关注调落物添加后土壤内细菌的变化, 而我们的研究着眼于调落物内细菌的变化。酸杆菌 门被认为是寡营养和嗜酸的细菌, 能生长在复杂的 聚合物中, 包括植物半纤维素或纤维素和真菌壳 (Eichorst et al., 2011)。酸杆菌门在葟营养环境下丰 度较高(Jones et al., 2009), 有研究发现酸杆菌门的 丰度与土壤有机碳含量和 $\mathrm{pH}$ 值呈显著负相关关系 (Jones et al., 2009), 但是, Fierer等(2007)的研究表明 土壤酸杆菌相对丰度与土壤有机碳含量和土壤 $\mathrm{C}: \mathrm{N}$ 呈显著正相关关系, 而我们并未发现细根分解物内 酸杆菌相对丰度与初始化学性质之间具有明显的相 关性(表4)。这可能是因为研究对象的差异, 该研究 主要针对土壤酸杆菌, 而我们的研究涉及细根调落 物内酸杆菌, 两个研究对象养分有效性不同, 从而 导致所能支持的微生物类群和数量的差异(Taylor et $a l ., 1989)$ 。其次, 我们的研究主要是在固定站点, 样 品量少, 这也可能是一个主要原因。在纲水平上, $\alpha-$ 变形菌纲、 $\beta$-变形菌纲、 $\gamma$-变形菌纲、不明放线菌 纲、鞘脂杆菌纲丰度较高, 且 $\alpha$-变形菌纲和不明放 线菌纲在不同树种之间差异显著(图4A, $p<0.05$ )。 张明锦(2016)的结果显示 $\alpha$-变形菌纲在不同的根系 中差异显著, 我们的结果与之一致。刺槐内 $\alpha$-变形 菌纲的丰度显著高于其他 3 个树种(图4A), $\alpha$-变形菌 纲相对丰度与初始 $\mathrm{N}$ 含量呈显著正相关关系(表5)。 研究显示, $\alpha$-变形菌包括大量参与 $\mathrm{C} 、 \mathrm{~N}$ 循环的细菌, 以及与植物共生的细菌(如根瘤菌属)(Soares et al., 2006)。这也是豆科植物刺槐根系调落物内 $\alpha$-变形菌 纲相对丰度显著高于其他 3 个树种(图4A), $\alpha$-变形菌 纲相对丰度与调落物分解速率呈显著正相关关系 (表5)的原因。 $\gamma$-变形菌中绝大多数为假单胞菌 (Pseudomonas), 其具有很强的分解能力, 增殖速度 快。 $\beta$-变形菌包括很多好氧或兼性细菌, 通常其降 解能力可变。鞘脂杆菌纲有利于凋落物中纤维素的 降解, 放线菌纲能促使调落物迅速腐烂, 是几丁质 和木质素分解的重要参与者(Zhao et al., 2016), $\gamma$-变 形菌纲中的某些种群在磷元素释放中具有重要作用
(Zhao et al., 2016), 这些菌群对生态系统C、N循环 有重要的作用。Zhao等(2016)的研究结果显示, 川西 亚高山森林叶调落物分解过程中细菌群落以 $\gamma$-变形 菌纲、鞘脂杆菌纲和黄杆菌纲为主要类群。我们的 结果与之存在差异, 主要原因可能是: 1)调落物基 质不同: 我们的研究是细根分解, 而该研究是针对 叶片调落物; 2)分解微环境存在差异: 该研究所处 环境是亚高山地区, 且分解置于土壤表面, 而我们 的实验在暖温带地区, 且放置于土壤中; 3) 测定微 生物的手段不同。该研究采用PCR-DGGE, 而我们 采用高通量测序技术。

致谢 感谢泰山森林生态系统定位研究站提供野外 基础支持。

\section{参考文献}

Adam SW, Zacchaeus GC, Cindy ML (2013). Contrasting rRNA gene abundance patterns for aquatic fungi and bacteria in response to leaf-litter chemistry. Freshwater Science, 32, 663-672.

Barret M, Morrissey JP, O'Gara F (2011). Functional genomics analysis of plant growth-promoting rhizobacterial traits involved in rhizosphere competence. Biology and Fertility of Soils, 47, 729-743.

Chapman SK, Koch GW (2007). What type of diversity yields synergy during mixed litter decomposition in a natural forest ecosystem? Plant and Soil, 299, 153-162.

Chigineva NI, Aleksandrova AV, Tiunov AV (2009). The addition of labile carbon alters litter fungal communities and decreases litter decomposition rates. Applied Soil Ecology, 42, 264-270.

Coûteaux M, Bottner P, Berg B (1995). Litter decomposition, climate and litter quality. Tree, 10, 63-66.

Ding XJ, Jing RY, Huang YL, Chen BJ, Ma FY (2017). Bacterial structure and diversity in rhizosphere and nonrhizosphere of Robinia pseudoacacia in the Yellow River Delta. Acta Pedologica Sinica, 54, 1293-1302. [丁新景, 敬如岩, 黄雅丽, 陈博杰, 马风云 (2017). 黄河三角洲 刺槐根际与非根际细菌结构及多样性. 土壤学报, 54, 1293-1302.]

Eichorst SA, Kuske CR, Schmidt TM (2011). Influence of plant polymers on the distribution and cultivation of bacteria in the phylum Acidobacteria. Applied and Environmental Microbiology, 77, 586-596.

Elser JJ, Acharya K, Kyle M (2003). Growth rate-stoichiometry couplings in diverse biota. Ecology Letters, 6, 936-943.

Fierer N, Bradford MA, Jackson RB (2007). Toward an ecological classification of soil bacteria. Ecology, 88, 1354-1364. 
Gessner MO, Chauvet E, Dobson M (1999). A perspective on leaf litter breakdown in streams. Oikos, 85, 377-384.

Grier CC (1981). Biomass distribution and above- and belowground production in young and mature Abies amabilis zone ecosystems of the Washington Cascades. Canadian Journal of Forest Research, 11, 155-167.

Gui H, Purahong W, Hyde KD, Xu JC, Mortimer PE (2017). The arbuscular mycorrhizal fungus Funneliformis mosseae alters bacterial communities in subtropical forest soils during litter decomposition. Frontiers in Microbiology, 8, $1-11$.

Hultman J, Waldrop MP, Mackelprang R, David MM, McFarland J, Blazewicz SJ, Harden J, Turetsky MR, McGuire AD, Shah MB, VerBerkmoes NC, Lee LH, Mavrommatis K, Jansson JK. (2015). Multi-omics of permafrost, active layer and thermokarst bog soil microbiomes. Nature, 521, 208-212.

Jones RT, Robeson MS, Lauber CL, Hamady M, Knight R, Fierer N (2009). A comprehensive survey of soil acidobacterial diversity using pyrosequencing and clone library analyses. The ISME Journal, 3, 442-453.

Kennedy AC (1999). Bacterial diversity in agroecosystems. Agriculture Ecosystems and Environment, 74(1-3), 65-76.

Kersters K, De Vos P, Gillis M, Swings J, Vandamme P, Stackebrandt E (2006). Introduction to the Proteobacteria. The Prokaryotes, 5(3), 4-37.

Luo YQ, Zhao XY, Wang T, Li YQ, Zuo XA, Ding JP (2017). Plant root decomposition and its responses to biotic and abiotic factors. Acta Prataculturae Sinica, 26(2), 197-207. [罗永清, 赵学勇, 王涛, 李玉强, 左小安, 丁杰萍 (2017). 植物根系分解及其对生物和非生物因素的响应 机理研究进展. 草业学报, 26(2), 197-207.]

Lydell C, Dowell L, Sikaroodi M, Gillevet P, Emerson (2004). A population survey of members of the phylum Bacteroidetes isolated from salt marsh sediments along the east coast of the United States. Microbial Ecology, 48, 263-273.

McLaren JR, Turkington R (2010). Plant functional group identity differentially affects leaf and root decomposition. Global Change Biology, 16, 3075-3084.

Meentemeyer V (1978). Macroclimate and lignin control of litter decomposition rates. Ecology, 59, 465-472.

Rong L, Li XW, Zhu TH, Zhang J, Yuan WY, Wang Q (2009). Varieties of soil microorganisms decomposing Betula luminifera fine roots and Hemarthria compressa roots. Acta Prataculturae Sinica, 18(4), 117-124. [荣丽, 李贤伟, 朱 天辉, 张健, 袁渭阳, 王巧 (2009). 光皮桦细根与扁穗 牛鞭草草根分解的土壤微生物数量及优势类群. 草业 学报, 18(4), 117-124.]

Sauvadet M, Chauvat M, Cluzeau D, Maron PA, Villenave C, Bertrand I (2016). The dynamics of soil micro-food web structure and functions vary according to litter quality. Soil Biology \& Biochemistry, 95, 262-274.
Shen YF, Wang N, Cheng RM, Xiao WF, Yang S, Guo Y, Lei L, Zeng LX, Wang XR (2017). Characteristics of fine roots of Pinus massoniana in the Three Gorges Reservoir Area, China. Forests, 8(6), 1-13.

Soares RA, Roesch LFW, Zanatta G, De Oliveira Camargo FA, Passaglia LMP (2006). Occurrence and distribution of nitrogen fixing bacterial community associated with oat (Avena sativa) assessed by molecular and microbiological techniques. Applied Soil Ecology, 33, 221-234.

Sun CL, Zhang G, Cheng RJ, Zhu LQ, Ding JB, Chang WS (2017). Microbial community structure and diversity of sheepfold atmosphere by 16S rRNA high-throughput sequencing. Acta Veterinaria et Zootechnica Sinica, 48, 1314-1322. [孙翠丽, 张阁, 程汝佳, 朱良全, 丁家波, 常维山 (2017). 16S rRNA高通量测序方法检测羊圈空 气微生物群落结构及多样性。畜牧兽医学报, 48 , 1314-1322.]

Sun H, Wang QX, Liu N, Li L, Zhang CG, Liu ZB, Zhang YY (2017). Effects of different leaf litters on the physicochemical properties and bacterial communities in Panax ginseng-growing soil. Applied Soil Ecology, 111, 17-24.

Taylor BR, Parkinson D, Parsons WFJ (1989). Nitrogen and lignin content as predictors of litter decay rates: A microcosm test. Ecology, 70, 97-104.

Tuomi M, Thum T, Jarvinen H, Fronzek S, Berg B, Harmon M, Trofymow JA, Sevanto S, Liski J (2009). Leaf litter decomposition-Estimates of global variability based on Yasso07 model. Ecological Modeling, 220, 3362-3371.

Urbanová M, Šnajdr J, Baldrian P (2015). Composition of fungal and bacterial communities in forest litter and soil is largely determined by dominant trees. Soil Biology \& Biochemistry, 84, 53-64.

Větrovský T, Baldrian P (2015). An in-depth analysis of actinobacterial communities shows their high diversity in grassland soils along a gradient of mixed heavy metal contamination. Biology and Fertility of Soils, 51, 827-837.

Wardle DA, Bardgett RD, Klironomos JN, Setälä H, van der Putten WH, Wall DH (2004). Ecological linkages between aboveground and belowground biota. Science, 304, 1629-1633.

Wymore AS, Salpas E, Casaburi G, Liu CM, Price LB, Hungate BA, McDowell WH, Marks JC (2018). Effects of plant species on stream bacterial communities via leachate from leaf litter. Hydrobiologia, 807, 131-144.

Zhang CH, Zhang LM, Liu XR, Xin XP, Li SG (2011). Root tissue and shoot litter decomposition of dominant species Stipa baicalensis in Hulun Buir meadow steppe of Inner Mongolia, China. Chinese Journal of Plant Ecology, 35, 1156-1166. [张彩虹, 张雷明, 刘杏认, 辛晓平, 李胜功 (2011). 呼伦贝尔草甸草原优势种贝加尔针茅根系组织 和地上部分调落物的分解. 植物生态学报, 35 , 1156-1166.] 
Zhang MJ (2016). Effects of Forest Gap Disturbance on Microbial Biomass and Bacterial Community Structure in the Process of Foliar Litter Decomposition. Master degree dissertation, Sichuan Agricultural University, Chengdu. [张明锦 (2016). 林窗干扰对调落叶分解过程中微生物 生物量和细菌群落结构的影响. 硕士论文, 四川农业大 学, 成都.]

Zhang MJ, Zhang J, Ji TW, Liu H, Li X, Zhang Y, Yang WQ, Chen LH (2015). Influence of forest gap on bacterial community structure and diversity during litter decomposition. Ecology and Environment Sciences, 24, 1287-1294. [张明锦, 张健, 纪托未, 刘华, 李勋, 张艳, 杨万勤, 陈 良华 (2015). 林窗对调落物分解过程中细菌群落结构 和多样性的影响. 生态环境学报, 24, 1287-1294.]

Zhang YG, Cong J, Lu H, Yang CY, Yang YF, Zhou JZ, Li DQ
(2014). An integrated study to analyze soil microbial community structure and metabolic potential in two forest types. PLOS ONE, 9, e93773. DOI: 10.1371/journal.pone.0093773.

Zhao BY, Xing P, Wu QL (2017). Microbes participated in macrophyte leaf litters decomposition in freshwater habitat. FEMS Microbiology Ecology, 93, fix108. DOI: 10.1093/ femsec/fix108.

Zhao YY, Wu FZ, Yang WQ, Tan B, He W (2016). Variations in bacterial communities during Foliar litter decomposition in the winter and growing seasons in an alpine forest of the eastern Tibetan Plateau. Canadian Journal of Microbiology, 62, 1-14. 